\title{
Estudo do comportamento de diferentes tipos de cimentos na mitigação das Reações Álcali-Agregado (RAA)
}

\author{
Marina Munaretto. Copetti ${ }^{1}$, Cristiane Carine dos. Santos ${ }^{2}$, Tássia. Fanton ${ }^{3 *}$, Ana Paula Maran ${ }^{4}$, \\ Cristian Dauinheimer Miranda ${ }^{5}$ \\ tassiafanton@gmail.com \\ ${ }^{1}$ Secretaria Acadêmica, Universidade Federal de Santa Maria, Cachoeira do Sul, Brasil \\ ${ }^{2}$ Departamento de Engenharia Sanitária e Ambiental, Universidade Federal de Santa Maria, Santa Maria, Brasil \\ ${ }^{3}$ Programa de Pós-Graduação em Engenharia Civil, Universidade Federal de Santa Maria, Santa Maira, Brasil. \\ ${ }^{4}$ Secretaria Acadêmica, Universidade Federal de Santa Maria, Cachoeira do Sul, Brasil \\ ${ }^{5}$ Universidade Regional Integrada do Alto Uruguai e das Missões, Santo Ângelo, Brasil
}

\begin{abstract}
RESUMO
A Reação Álcali-Agregado (RAA) resulta na manifestação de expansões, ocasionando sérios efeitos em estruturas de concreto. Buscando meios de mitigar estes efeitos, se desenvolveu esta pesquisa com o objetivo de realizar um estudo comparativo da mitigação da expansão da RAA em barras de argamassa pelo método acelerado, conforme estabelece a ABNT NBR 15577-5. Para tal estudo foram utilizadas composições de agregado reativo, confirmado por meio de analise petrográfica, com aglomerantes cimentícios dos tipos CP II F 32, CPII E 40, CP IV e CP V com adição de $8 \%$ de metacaulim, sendo o CPIV o que apresentou o melhor desempenho. Verificou-se que além do equivalente alcalino, a presença de adições também tem uma grande influência na RAA.
\end{abstract}

Palavras- chave: RAA; Patologia; Concreto; Adições minerais; Agregado reativo. 


\section{INTRODUÇÃO}

O concreto é um dos materiais mais antigos e que tem o uso mais disseminado na construção civil. Fazem parte da sua composição aglomerante hidráulico - cimento Portland, agregado miúdo, agregado graúdo, água, podendo ainda conter aditivos químicos e adições. Algumas propriedades fazem com que esse material seja o mais aplicado na engenharia, desde a facilidade de executar elementos diversos, em variedade de dimensões e geometria, ao baixo custo e maior disponibilidade.

As primeiras publicações sobre reação álcali-agregado, reação esta que ocorre entre os álcalis do concreto em estado endurecido, datam o ano de 1916 no Brasil, mas houve estudos maiores no ano 1963. A preocupação maior sempre foi com obras de grande porte como barragens, e parte de usinas hidrelétricas. Mas por volta de 2004, na cidade de Recife foram identificados casos dessa patologia em edifícios acometendo blocos e sapatas de fundações com idades entre 3 a 20 anos. Com o aumento de conhecimento na área, percebeu-se uma incidência na maioria dos estados brasileiros com maior volume no Nordeste.

\section{PATOLOGIAS DO CONCRETO}

Os fenômenos patológicos habitualmente apresentam manifestação externa característica, a partir da qual se pode ter uma ideia dedutiva quanto à natureza, à origem e aos mecanismos dos fenômenos envolvidos.

A retração e fluência estão entre os principais fatores que afetam a integridade de uma estrutura em concreto, podendo citar também a Reação Álcali-Agregado (RAA), pois sua característica expansiva a torna uma manifestação patológica de difícil controle e tratamento, podendo produzir degradação significativa da resistência e rigidez do concreto em diferentes tipos de estruturas. (Balabuch, Felix, Carrazedo, 2019).

No mundo, em aproximadamente 35 países, existem diversas obras com estruturas de concreto afetadas por reação álcali-agregado. Antigamente, quando se falava em reação álcali-agregado, pensava-se em obras de barragem e obras de grande porte. Atualmente as reações podem ser encontradas em diversos tipos de estruturas de concreto por isso os órgãos que estudam o concreto com mais afinco desenvolveram um guia prático para prevenção de reação álcali-agregado, guia prático para inspeção e diagnóstico da reação álcali-agregado e também um guia de ação frente as estruturas afetadas pela reação álcali agregado em conjunto com a ABNT 15577 (BATTAGIN, SILVEIRA \& MUNHOZ,2016).

A deterioração induzida pela RAA nos compósitos cimentícios é um problema sério sem nenhuma solução simples, embora existam inúmeros métodos tradicionais que tentam impedir esta reação tais como a escolha do agregado de maneira adequada e que não seja reativo; a utilização de cimentos com um teor alcalino baixo; a adição de materiais pozolânicos e assim por diante, o fato é que este problema é cada vez mais presente em concretos de cimento Portland. Além disso, a reparação das estruturas afetadas é um empreendimento muito caro. (BALABUCH, 2018).

A fissuração que ocorre no concreto devido à RAA pode contribuir com outros problemas que afetam a durabilidade das estruturas como, por exemplo, a corrosão das armaduras. Segundo o CBDB (Comitê Brasileiro de Barragens, 1999), a micro-fissuração junto à superfície dos agregados e a perda de aderência podem levar a perdas de resistência e à redução do módulo de elasticidade do concreto.

Assim sendo, esta pesquisa sobre adições minerais e tipos de cimento, na atenuação da reação álcali-agregado ocorrida nas estruturas de concreto por ela afetadas, mostra-se relevante para o desenvolvimento do conhecimento técnico-científico sobre o assunto. 


\subsection{Reação Álcali-agregado (RAA)}

A RAA é um tipo de reação expansiva bastante conhecida devido ao grande número de casos registrados no mundo. A RAA ocorre devido ao processo químico que provém da reação dos compostos mineralógicos do agregado com hidróxidos alcalinos originários do cimento, água de amassamento e agentes externos, os quais estão dissolvidos na solução dos poros de concreto. O produto resultante dessa reação é um gel cristalino expansivo na presença de umidade, podendo originar fissuras, aumento de permeabilidade, diminuição da resistência e consequentemente a ruptura da estrutura. Por trazer tanto risco as obras civis e não havendo um método eficiente na solução desse problema quando instalado a melhor solução técnico/econômica para se combater a RAA é a prevenção (SANCHEZ,KUPERMAN, HELENE,2008).

Os ensaios, regidos pela norma NBR 15577-1(2018), estabelecem limites de expansão em um determinado corpo-de-prova, concluindo se este é potencialmente reativo ou potencialmente inócuo. A utilização de areia considerada reativa em concreto, somada a um ambiente úmido, geram patologias muitas vezes irreversíveis. A fim de evitar esse problema, adiciona-se material de característica pozolânica que, em algumas quantidades inibem a reação, tornando o agregado que antes era considerado potencialmente reativo, em potencialmente inócuo, conhecido como mitigação.

A deterioração do concreto causada pela reação álcali-agregado foi identificada pela primeira vez no ano de 1940, na Califórnia - EUA, por Stanton, quando se constatou inexplicáveis expansões em estruturas de diversos prédios escolares, pontes, pavimentos e construções portuárias. Ao investigar, Stanton chegou a conclusão que as expansões estavam relacionadas ao uso de cimento com alto teor de álcalis e que as deteriorações ocorridas foram devido à reação álcali-sílica (HOBBS, 1988).

A reação se manifesta no concreto por um padrão de fissuração, expansão e consequente deslocamento dos elementos estruturais, o que causa ainda a desagregação de fragmentos da superfície. Algumas vezes, ocorre a exsudação de gel sílico-alcalino resultante da reação, que se deposita na superfície do concreto (PAULON, 1981). Segundo Bonato (2015), a reação álcaliagregado, é a reação química que ocorre no interior de uma estrutura de concreto, acontece entre os álcalis do cimento e os minerais dos agregados, sendo que geralmente os álcalis ou hidróxidos alcalinos também podem advir da água de amassamento, de aditivos químicos, de adições pozolânicas, entre outros.

No Brasil, existe uma norma específica para a análise da reatividade álcali-agregado: ABNT NBR 15577 (2018). Esta norma está dividida em 6 partes:

- Parte 1: Guia para avaliação da reatividade potencial e medidas preventivas para uso de agregados em concreto;

- Parte 2: Coleta, preparação e periodicidade de ensaios de amostras de agregados para concreto;

- Parte 3: Análise petrográfica para verificação da potencialidade reativa de agregados em presença de álcalis do concreto.

- Parte 4: Determinação da expansão em barras de argamassa pelo método acelerado;

- Parte 5: Determinação da mitigação da expansão em barras de argamassa pelo método acelerado;

- $\quad$ Parte 6: Determinação da expansão em prismas de concreto.

As reações álcali-agregado podem ser de três tipos: reação álcali-sílica, reação álcali-silicato e reação álcali-carbonato, cada tipo dependente da composição mineralógica reativa do agregado. Diante aos problemas gerados por essas reações, diversos estudos têm procurado maneiras de minimizar estes efeitos. De acordo com Monteiro et al. (1997), a ação mais empregada para 
minimizar e até suprimir a reação álcali-agregado é substituir parcialmente o cimento por adições minerais, principalmente materiais pozolânicos.

Os materiais pozolânicos que são comumente utilizados para substituir parcialmente o cimento Portland, são a cinza volante, cinza de casca de arroz, escória de alto forno e sílica ativa.

\subsection{Uso de adições minerais para mitigação de RAA}

Segundo Mehta (2008), a utilização de adições minerais tem influência benéfica sobre a durabilidade do concreto, devido aos efeitos físicos associados com o tamanho das partículas, que são geralmente mais finas que as do cimento Portland, e pelas reações pozolânicas e cimentíceas. De acordo com a ASTM C 618/19 e a ABNT NBR 12653: 2015, pozolana é um material que, por si só, possui pouca ou nenhuma atividade cimentícea, porém, quando finamente dividida e na presença de água, reage com o hidróxido de cálcio à temperatura ambiente para formar compostos com propriedades cimentantes, reação na qual é chamada de reação pozolânica.

As pozolanas podem se originar tanto de materiais naturais como: tufos vulcânicos, terras diatomáceas, argilas calcinadas; assim como de subprodutos e resíduos industriais (cinza volante, sílica ativa e cinza de casca de arroz). Elas podem ser utilizadas como substituição de parte do cimento ou como adição em percentuais variáveis em relação à massa de cimento. A adição de materiais pozolânicos, além de combaterem a expansão causada pela reação álcali-agregado, melhora outras propriedades do concreto, como a permeabilidade, a resistência ao calor, a difusividade, e o tamanho da zona de transição, devido à presença de partículas sólidas menores. Existem muitas proposições que buscam explicar o efeito da incorporação de adições minerais pozolânicas na reação álcali-agregado.

Segundo TIECHER (2006) as adições pozolânicas impedem a reação álcali-agregado pois ao reagirem com o hidróxido de cálcio do cimento Portland provocam uma diminuição do $\mathrm{pH}$ da solução dos poros, inibindo assim a reação.

Outro fator que combate a RAA com adições minerais é que a sílica presente nestas reage com os álcalis do CP antes da sílica presente nos agregados do concreto, e esta reação que ocorre primeiramente não é prejudicial, pois o produto silicoso, finamente dividido, é inofensivo por não acarretar em expansões (DIAMOND, 1984, apud TIECHER, 2006).

Atualmente no Brasil são produzidos cimentos Portland com variadas porcentagens de adições, nessas opções têm-se dois tipos com altas porcentagens de adições, que podem ser usados para prevenirem o desencadeamento da reação álcali-agregado.

\section{METODOLOGIA}

Em virtude do histórico encontrado em fundações de subestações na região central de Minas Gerais fez-se um estudo meticuloso para evitar futuros problemas, o agregado em questão não poderia ser alterado devido distância da obra. Então buscou-se fazer um estudo comparativo de mitigação apenas trocando o aglomerante da mistura para encontrar melhor solução para evitar esse propenso problema.

\subsection{Agregado e aglomerantes}

Nesse estudo foi utilizado o agregado da cidade de Salinas do estado de Minas Gerais foram realizados coleta e ensaios de agosto de 2018 a fevereiro de 2019. Foram recolhidos os agregados, tipos de cimentos e metacaulim e realizado o estudo de mitigação.

Estudos anteriores (relatórios $\mathrm{ABCP}$ ) indicaram que essa região tem agregados potencialmente reativos. Com o intuito de contribuir com subsídios para a mitigação da expansão desses agregados 
foi realizado o ensaio prescrito pela NBR 15577-5, onde usou os cimentos (CP IV 32 - CP II E 40 - CP II F 40 e CP V + 8\% de metacaulim).

Portanto, este estudo apresenta os resultados dos ensaios referentes à determinação da mitigação da expansão em barras de argamassa pelo método acelerado prescrito pela ABNT NBR 15577-5, indicado para avaliar a eficiência de cimentos com adições de materiais pozolânicos ou escórias de alto-forno em inibir a expansão de agregados classificados como potencialmente reativos pela metodologia prescrita pela ABNT NBR 15577-4. O tipo de cimento variou conforme estudo, onde o agregado foi o mesmo em todo o estudo.

\subsubsection{Análise petrográfica}

A análise petrográfica dos agregados foi realizada seguindo as prescrições normativas da NBR 15577-3 e efetuando-se a visualização das amostras por técnicas microscópicas para se determinar as características mineralógicas dos agregados. O diagnóstico do agregado quanto a sua reatividade também foi feito em função da presença de minerais reativos e a avaliação do ângulo de extinção ondulante identificado no quartzo tensionado via microscopia de luz polarizada, de acordo com o procedimento descrito por Dolar-Mantuani (1983).

Na Figura 1 segue esquematizada a determinação do ângulo de extinção ondulante em microscópio petrográfico. O objetivo é avaliar a qualidade da brita como agregado para concreto do ponto de vista mineralógico, no que se refere a sua potencialidade à reação álcali-agregado (RAA).
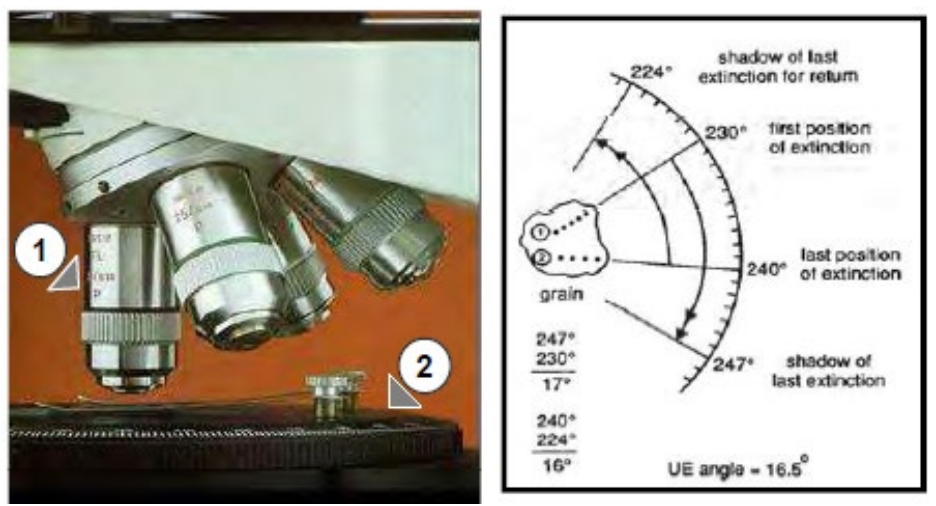

Figura 1 -Análise petrográfica. a) Detalhe do microscópio petrográfico - objetivas (1) e mesa giratória (2); b) Determinação do ângulo de extinção ondulante na mesa giratória. Fonte: MANTUANI, 1981 apud POOLE, (1992).

\subsubsection{Método Acelerado de Barras de Argamassa}

O ensaio acelerado em barras de argamassa foi realizado para a determinação da propensão dos agregados estudados à reação álcali-agregado. O Método Acelerado de Barras de Argamassa é normatizado no pela ASTM C-1260 (2014) e ABNT NBR 15577-4 (2018), e é, devido à sua velocidade de avaliação, o método mais utilizado no mundo (SANCHEZ, 2008).

O ensaio consiste na confecção e imersão de barras de argamassa em uma solução de hidróxido de sódio a $80^{\circ} \mathrm{C}$ por um período de 30 dias, fazendo-se leituras de expansão aos 16 e 30 dias contados a partir de sua moldagem, e em períodos intermediários (ABNT NBR 15577-4, 2018). No instante de moldagem foram controladas as condições do ambiente (umidade e temperatura) por meio de um relógio termo-higrômetro. Após $24 \pm 2 \mathrm{~h}$ de cura nos moldes, efetuou-se o acondicionamento das barras em recipiente com água destilada, mantendo-se na temperatura de $800 \mathrm{C}$ durante $24 \square 2 \mathrm{~h}$.Seqüencialmente, realizou-se a primeira medição das barras, sendo as mesmas posteriormente transferidas para um banho térmico de $\mathrm{NaOH} 1 \mathrm{~N}$ a $800 \mathrm{C}$. 
A Figura 2 demonstra onde as amostras receberam o banho térmico $\mathrm{NaOH} 1 \mathrm{~N}$ controlado à $800^{\circ} \mathrm{C}$.

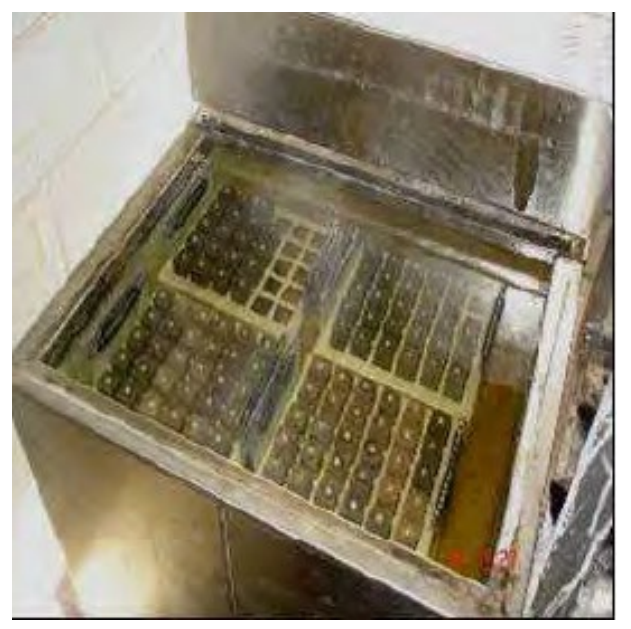

Figura 2 - Banho térmico $\mathrm{NaOH} 1 \mathrm{~N}$ controlado à 800C. Fonte: Próprio Autor (2020).

A retirada e retorno de cada barra do banho térmico para leitura foi realizado num período de tempo inferior a $1 \mathrm{~min}$. A Figura 3 representa a retirada das amostras para as leituras.

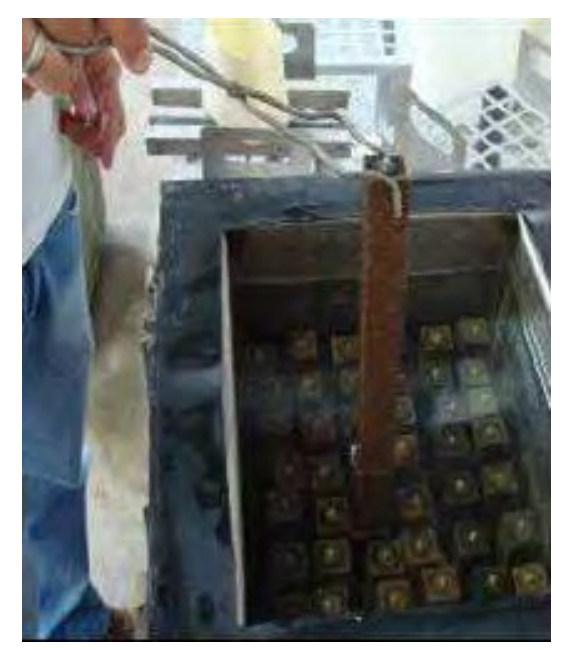

Figura 3- Instante de retirada da barra do banho térmico. Fonte: Próprio autor (2020).

A ASTM C-1260 (2014) define um limite de expansão de 0,20\% aos 16 dias, acima do qual a reação é considerada deletéria.

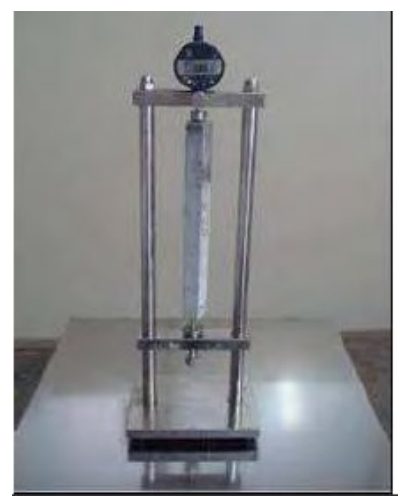

Figura 4 - Equipamento de leitura de expansões. Fonte: Próprio autor (2020). 
Expansões entre $0,10 \%$ e $0,20 \%$ são classificadas como potencialmente deletérias, e abaixo de 0,10\%, como inócuas. Já a ABNT NBR 15577-4 (2018) classifica como potencialmente inócua a reação com expansão abaixo de $0,19 \%$ aos 30 dias, e acima desse limite como potencialmente reativa.

No caso da avaliação da mitigação da reação álcali-agregado pelo método acelerado NBR 155775, foi testada a mistura: (Brita + CP IV RS - 32), (Brita + CP II Z 40), (Brita + CP II F - 32) e (Brita + CP V ARI - RS $+8 \%$ de metacaulim). Substituiu-se o metacaulim em cima da massa de cimento, ou seja 404,8 g de cimento e $35,8 \mathrm{~g}$ de metacaulim.

A Tabela 1 apresenta a composição dos materiais utilizada para a preparação de três barras de argamassa de $(25 \times 25 \times 285) \mathrm{mm}$. A amostra de agregado foi previamente britada e pulverizada, utilizando-se um britador de mandíbulas, marca Renard, modelo

BMA 125.80, em seguida peneirada até obtenção da distribuição granulométrica indicada. Este procedimento foi realizado em todas as amostras. A quantidade de materiais utilizadas em cada moldagem das barras é a mesma, o que muda é o aglomerante. O aglomerante A é o cimento CP IV RS 32, o aglomerante B é o cimento CP II F 40 e o aglomerante CP II E 40 e o aglomerante D é o CP V + METACAULIM.

Tabela 1 - Composição dos materiais

\begin{tabular}{|c|cc|c|}
\hline \multicolumn{2}{|c|}{ Abertura nominal das peneiras (mm) } & Massa (g) \\
\hline \multirow{4}{*}{ Agregado } & $4,8-2,4$ & 99,0 \\
\cline { 2 - 3 } & $2,4 \quad-1,2$ & 247,5 \\
\cline { 2 - 3 } & $1,2-0,6$ & 247,5 \\
\cline { 2 - 3 } & $0,6-0,3$ & 247,5 \\
\cline { 2 - 3 } & $0,3-0,15$ & 148,5 \\
\hline Cimento A, B, C e D. & 440,0 \\
\hline \multicolumn{2}{|c|}{ Água destilada (a/c = 0,47) } \\
\hline
\end{tabular}

\section{RESULTADOS E DISCUSSÕES}

\subsection{Análise petrográfica}

A análise petrógrafica foi realizada primeiramente ao microscópio estereoscópico, sendo complementada por observações de lâmina delgada ao microscópio óptico de luz transmitida. A Tabela 2 demonstra a síntese das características petrográficas.

Tabela 2 - Síntese das características petrográficas.

Mineralogia
Quartzo 


\begin{tabular}{|c|c|}
\hline Subordinada & Opacos, carbonatos, sericita \\
\hline Reativa/Deletéria & Quartzo microgranular(20-30\%) \\
\hline Cor & Cinza escuro \\
\hline Estrutura & Foliada \\
\hline Textura & Granolepidoblástica/ Xistosa \\
\hline Granulação & $\begin{array}{l}\text { Inequigranular. Média }(5 \mathrm{~mm} \text { a } 1 \mathrm{~mm}) \text { a } \\
\text { fina }(<1 \mathrm{~mm})\end{array}$ \\
\hline Deformação do agregado & Foliação marcada pela orientação das micas \\
\hline Feldspato(Texturas potencialmente reativas) & Não ocorre \\
\hline Quartzo deformado(<extinção ondulante) & $15^{\circ}$ a $30^{\circ}$ \\
\hline Quartzo microgranular(\%) & $>15 \%$ \\
\hline Microfissuração & Fraco \\
\hline Tipo & Rocha britada \\
\hline Grau de alteração & Rocha sã \\
\hline Propriedades físico-mecânicas & Rocha muito coerente \\
\hline Tipo de rocha & Metamórfica \\
\hline Classificação petrográfica & Quartzo xisto \\
\hline Reatividade potencial & Potencialmente reativa \\
\hline
\end{tabular}

A rocha é constituída principalmente por quartzo e feldspato dispostos em uma textura granolepidoblástica xistosa, podendo-se classificar a rocha como um quartzo de xisto. Por meio do estudo petrográfico a amostra foi considerada potencialmente reativa com relação a sua reatividade frente aos álcalis do concreto. A reatividade da amostra está relacionada à presença de quartzo microgranular em teores de $15 \%$ constituintes totais da amostra.

\subsection{Método Acelerado de Barras de Argamassa}

Os ensaios acelerados em barras de argamassa foram realizados com agregado potencialmente reativo. Os ensaios de reatividade foram realizados até a idade de 28 dias, como especifica a norma. O gráfico ilustrado na figura 5 , apresenta os resultados dos ensaios realizados utilizando o cimento CP IV RS - 32, CP II E 40, CP II F 32 e CP V + metacaulim destacando-se os valores aos 28 dias de cura em solução de $\mathrm{NaOH} 1 \mathrm{~N}$ a $80^{\circ} \mathrm{C}$.

A Figura 5 ilustra a evolução das expansões médias das barras de argamassa com o tempo de cura 


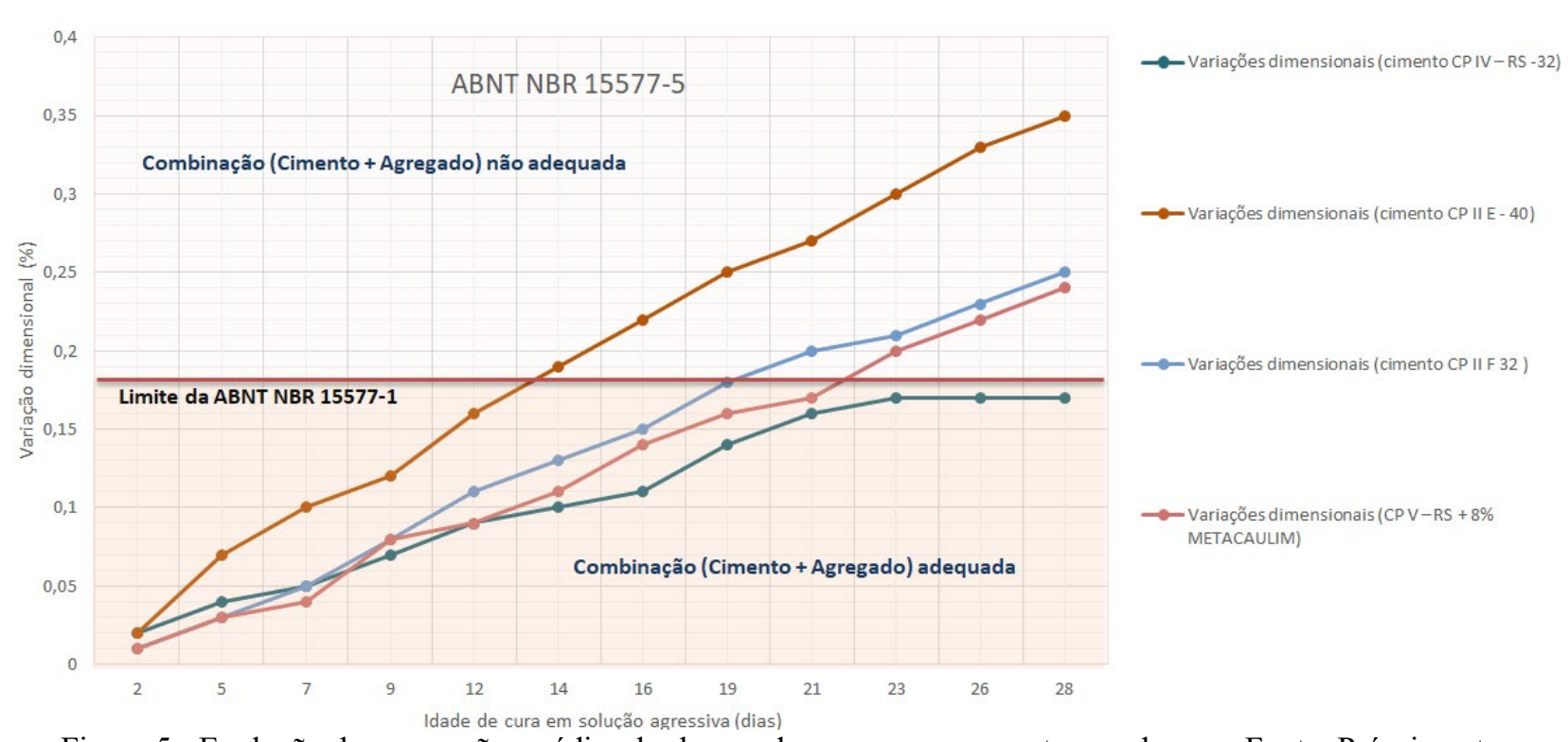

Figura 5 - Evolução das expansões médias das barras de argamassa com o tempo de cura. Fonte: Próprio autor (2021).

Com relação à avaliação da mitigação da reação álcali-agregado pelo método acelerado ABNT NBR 15577-5, a parte 1 da norma estabelece que a comprovação da mitigação da reação é obtida quando a expansão for menor que $0,19 \%$ aos 30 dias (28 dias de cura em solução alcalina).

\subsubsection{Amostra CP IV RS - 32}

A amostra que foi utilizado cimento CP IV RS-32, apresenta expansão for menor que $0,19 \%$ aos 28 dias, como pode ser analisado no gráfico ilustrado na figura 5 .

Em estudo realizado por TIECHER (2006), concluiu-se que o CP IV, ou cimento Pozolânico, gerou menores expansões comparando-se com os outros tipos de cimento, então se recomenda que na execução de grandes obras sujeitas a reação álcali-agregado seja utilizado o CP IV.

\subsubsection{Amostra CP II E 40}

Os ensaios acelerados indicaram a maior tendência à reação na amostra CP II 40, possuindo expansões elevadas nas primeiras idades, sendo aos 14 dias facilmente caracterizados como potencialmente reativo. Os cimentos CPII F32 E CPV + Metacaulim confirmaram sua reatividade aos 19 e 21 dias. O cimento CP IV apresentou-se dentro do índice sendo considerado não reativo.

\subsubsection{Amostra CP II F 32}

$\mathrm{O}$ agregado quando combinado com o cimento CP II-F-32 apresentou valor de expansão superior de $0,10 \%$ aos 14 dias de cura em solução alcalina, indicando que a combinação especificadamente ensaiada não é adequada, o agregado é reativo e esse tipo de cimento não conseguiu inibi-lo.

\subsubsection{Amostra CP V + 8\% metacaulim}

A amostra de brita (Salinas) quando combinada com o cimento (CP V ARI - RS adicionado 8\% de metacaulim), apresentou valor de expansão superior a $0,19 \%$ aos 28 dias de cura em solução alcalina, indicando que a combinação especificamente ensaiada não é adequada, o agregado é potencialmente reativo e o cimento não inibiu a expansão devido à reação álcali-agregado nos níveis requeridos.

A grande presença de gel característico da RAA no CPV-ARI está de acordo com os resultados apresentados por este no ensaio acelerado das barras de argamassa, em que foi o cimento que mais apresentou expansão, e o único em que a reação foi classificada como deletéria. 
Nem sempre é possível limitar os álcalis totais, principalmente em concreto mistura com alto teor de cimento. Nesse caso, a influência dos álcalis agressivos pode ser mitigada pelo uso de adições minerais, como escória granulada de alto-forno moída, cinzas volantes, sílica ativa ou metacaulim. Esses materiais reduzem e imobilizam os álcalis o suficiente para prevenir ou controlar o RAA. Essa prática foi aceita em todo o mundo e contribui também para a melhoria ambiental. No entanto, as próprias adições minerais podem contribuir com alguns álcalis à mistura. A vantagem das adições minerais é que elas têm um conteúdo alcalino ativo consideravelmente menor do que o cimento Portland, uma vez que seus álcalis geralmente estão amarrados em suas fases vítreas e são liberados a uma taxa muito mais lenta do que o cimento Portland. Os mecanismos pelos quais as adições minerais suprimem a expansão da RAA envolvem complexidade álcalis para reduzir as concentrações de íons hidroxila e alterar as taxas de difusão de álcalis e cálcio nos locais de reação, resultando na formação de produtos de reação não expansivos inofensivos.

Existem dois tipos de cinzas volantes, Classe F e Classe C (ASTM C618, 2019), distinguidas por seu teor de cal $(\mathrm{CaO})$, com cinzas de Classe $\mathrm{C}$ com maior teor de cal, geralmente excedendo $10 \%$ ou até $20 \%$. Para fins de prevenção do RAA expansivo, a proporção mínima permitida de $\mathrm{SiO}_{2} 1 \mathrm{Al}_{2} \mathrm{O}_{3} 1 \mathrm{Fe}_{2} \mathrm{O}_{3}$ para cinzas da classe $\mathrm{F}$ é de $70 \%$ e para cinzas da classe $\mathrm{C}$ é de $50 \%$. Um requisito adicional para cinzas volantes é um limite máximo de 1,5\% para os álcalis disponíveis, conforme determinado.

Ao analisar os resultados, podemos identificar que a amostra CP II 40 apresenta maior expansão, e a amostra CP IV RS-32 apresentou o melhor resultado, com expansão máxima aos 28 dias menor que 0,19 . Sendo assim pode-se considerar que o cimento CP IV RS-32, é o mais adequado para mitigar a reação álcali-agregado dentre as amostras analisadas.

\section{CONSIDERAÇÕES FINAIS}

A maneira óbvia de impedir a RAA é evitar o uso de agregados reativos a álcalis. Muitos tipos de rochas que ocorrem naturalmente são potencialmente reativos. Isso enfatiza a importância de testar fontes de agregados novas ou não testadas para RAA antes de serem usadas no concreto. No entanto, há ocasiões em que não é possível evitar um agregado reativo a álcalis. Nesses casos, a mistura com um agregado não reativo pode reduzir o problema. Outra medida é excluir os constituintes suscetíveis de RAA por beneficiamento (extração e trituração seletivas, separação de meios pesados, etc.). Como alternativa, deve-se prestar atenção à redução ou minimização dos álcalis na mistura ou modificação do ambiente para eliminar a umidade

Os resultados estão, em geral, de acordo com a bibliografia, que apresenta o CPV-ARI como pouco resistente à RAA, o CPIV-RS como bom inibidor, bom desempenho em contato com a reação álcali-agregado. Indícios da RAA, como a presença de gel, também são observados por diversos autores, mesmo para cimentos que não sofrem com a reação. O desempenho ruim do CPV-ARI, mesmo sendo o cimento com menor equivalente alcalino entre os avaliados, pode ser justificado por sua elevada pureza e ausência de adições capazes de controlar o desenvolvimento da reação álcali-agregado. De forma análoga, o bom desempenho do CPIV-RS tem como justificativa seu teor de até $50 \%$ de adição de material pozolânico, que promove reações capazes de inibir a RAA no cimento Portland. Desta forma, conclui-se que, além do equivalente alcalino, a presença de adições também tem uma grande influência na reação álcali-agregado no cimento Portland.

\section{REFERENCIAS}

ASSOCIAÇÃO BRASILEIRA DE NORMAS TÉCNICAS. NBR 15577-1, Agregados Reatividade álcali-agregado. Rio de Janeiro, 2018. 
ASSOCIAÇÃO BRASILEIRA DE NORMAS TÉCNICAS. NBR 12653, Materiais pozolânicos -Requisitos. Rio de Janeiro: ABNT, 2015.

AMERICAN SOCIETY FOR TESTING AND MATERIALS. Standard specification for coal fly ash and raw or calcined natural pozzolan for use in concrete. C618-19. Philadelphia, United States of America, 2019.

AMERICAN SOCIETY FOR TESTING AND MATERIALS. ASTM C1260. Standard Test Method for Potential Alkali Reactivity of Aggregates (Mortar-Bar Method), ASTM International, West Conshohocken, PA, 2014, www.astm.org.

BATTAGIN, A.; SILVEIRA, A.L.; MUNHOZ, F.; BATTAGIN, I. Associação Brasileira de Cimento Portland. A evolução da cultura da prevenção da reação álcali-agregado no mercado nacional. In: Concreto e construções. Ano 44. Ed. Ibracon, Jul-Set 2016.

BALABUCH, T. J. R.; FELIX, E. F.; CARRAZEDO, R. Modelagem numérica do concreto sujeito à reação álcali-agregado acoplada aos efeitos de retração e fluência. 2019.

BALABUCH, Tito José Rodrigues. Análise numérica das deformações do concreto sujeito à reação álcali-agregado considerando os efeitos de retração e fluência. 2018. Tese de Doutorado. Universidade de São Paulo.

BONATO, Luciano Cezar. Reação alcali-agregado, principais causas e estudo de reatividade potencial. 2015. Trabalho de Conclusão de Curso. Universidade Tecnológica Federal do Paraná.

COMITÊ BRASILEIRO DE BARRAGENS. Guia Básico de Segurança de Barragens, São Paulo, 1999.

DOLAR-MANTUANI, Ludmila. Handbook of concrete aggregates: A petrographic and technological evaluation. NOYES DATA CORP., MILL RD. AT GRAND AVE., PARK RIDGE, NJ 07656, USA, 1983, 345, 1983.

HOBBS, D. W.. Alkali-silica reaction in concrete. London: 1988.

MONTEIRO, P.J.M.; PREZZI, M. ; SPOSITO, G. The alkali-silica reaction, part L ACI Materials Journal, USA, v. 94, n. 1, p. 10-17,jan. 1997.

MEHTA, P. K.. Concreto Sustentável. Revista Téchne. São Paulo: 2008.

POOLE, A.B. Introduction to alkali-aggregate reaction in concrete. In: SWAMY, R. M. (Ed.). The Alkali-aggregate reaction in concrete. New York: Taylor \& Francis Elibrary, 2003. p. 1-29.

PAULON, V. A. Reações álcali-agregado em concreto. Escola Politécnica da Universidade de São Paulo. São Paulo, p. 125, 1981.

SANCHES, L.F.M. Contribuição ao estudo dos métodos de ensaio na avaliação das reações álcaliagregado em concretos. Dissertação (Mestrado), Universidade de São Paulo, Escola Politécnica, São Paulo, 2008. 170p. 
SANCHEZ, L., KUPERMAN, S., HELENE, P. Reação álcali-agregado - Método Acelerado Brasileiro de Prismas de Concreto (ABCPT). Anais de $50^{\circ}$ Congresso Brasileiro do Concreto CBC2008 - 50CBC0223, 2008.

TIECHER, Francieli. Reação álcali-agregado: avaliação do comportamento de agregados do sul do Brasil quando se altera o cimento utilizado. UFRGS, Porto Alegre, 2006. 